\title{
Eficiência energética em prédios públicos: análise da inserção de lâmpadas LED na UFERSA
}

\author{
Francisco Edson Gomes de Morais Júnior ${ }^{[1]}$, Fabiana Karla de Oliveira Martins Varella Guerra ${ }^{[2]}$ \\ [1] Universidade Federal Rural do Semi-árido; edson1809@live.com \\ [2] Universidade Federal Rural do Semi-árido; fkv@ufersa.edu.br \\ Recebido: $19 / 06 / 2020$; \\ Aceito: $27 / 07 / 2020$; \\ Publicado: 11/09/2020.
}

Resumo: Um dos principais gastos de um país é o consumo de energia elétrica, portanto reduzir de forma eficiente a energia elétrica é uma das alternativas almejadas. A iluminação, por exemplo, requer uma alta demanda de energia elétrica, utilizar de uma iluminação eficiente é uma forma de reduzir os custos de uma edificação. Estima-se que em 2018, cerca de 7\% de toda a energia produzida no Brasil foi consumida pelo poder público, e o consumo através da iluminação equivale a aproximadamente $1 / 3$ de uma edificação. Neste contexto, o presente trabalho avaliou o impacto da inserção e troca das lâmpadas fluorescentes tubulares por lâmpadas do tipo LED na Universidade Federal Rural do Semiárido em Mossoró-RN. O trabalho foi desenvolvido avaliando dois prédios da Instituição, no caso, Prédio Engenharias 1 e Prédio da Biblioteca. Para realização do trabalho, inicialmente foram identificados todos os ambientes dos prédios avaliados, e realizouse um quantitativo das lâmpadas e seus tipos, além de medição in loco da iluminância de cada ambiente. Posteriormente, os valores medidos antes e após a troca foram comparados. Com o intuito de visualizar o impacto dessa substituição da iluminação, foram realizadas pesquisas de satisfação com os usuários destes lugares, que avaliaram de forma satisfatória.

Palavras-chave: Lâmpadas LED; eficiência; energia; iluminação eficiente.

Abstract: One of the main expenditures of a country is the consumption of electricity, so reducing electricity efficiently is one of the desired alternatives. Lighting, for example, requires a high demand for electricity, using efficient lighting is a way to reduce building costs. It is estimated that in 2018 , about $7 \%$ of all energy produced in Brazil was consumed by the government, and consumption through lighting is equivalent to approximately $1 / 3$ of a building. In this context, the present work evaluated the impact of inserting and replacing tubular fluorescent lamps with LED-type lamps at the Universidade Federal Rural do Semi-árido in Mossoró-RN. The work was developed by evaluating two buildings of the Institution, in this case, building Engenharias 1 and building Biblioteca. In order to carry out the work, initially all the environments of the evaluated buildings were identified, and a number of lamps and their types were carried out, in addition to measuring in situ the illuminance of each environment. Subsequently, the values measured before and after the exchange were compared. In order to visualize the impact of this lighting replacement, satisfaction surveys were carried out with the users of these places, which they evaluated satisfactorily.

Key-words: LED Lamps, efficiency, energy, efficient lighting.

\section{INTRODUÇÃO}

$\mathrm{A}$ matriz energética brasileira é majoritariamente formada pela energia hidráulica, e de acordo com [1] cerca de $67 \%$ de toda a produção de energia elétrica vem da mesma. Esta proporção para a matriz energética é alta e qualquer distúrbio na produção de energia hidráulica tem grande impacto nas vidas dos consumidores. $\mathrm{O}$ clima brasileiro é composto basicamente de duas estações do ano, inverno e verão, onde notoriamente no período de inverno a geração hidráulica é maior e que consequentemente no verão a geração é menor, isto é 
diretamente conectado as bandeiras tarifárias já que nos 6 meses de inverno o consumidor paga tarifa verde, sendo esta sem nenhum custo adicional na conta de energia, já nos outros 6 meses, de verão, o consumidor paga tarifa amarela ou vermelha, o que proporciona uma tarifa adicional, gerando portanto, um custo maior em seu orçamento.

O consumo de energia elétrica, vem apresentando um crescimento exponencial, devido à inserção de novos consumidores ano após ano. Para suportar esse aumento crescente, as empresas que regem a distribuição, transmissão e geração de energia, estão constantemente a procura de maneiras que deixem os seus sistemas mais confiáveis, e este trabalho de alta confiabilidade gera um custo maior para todos que estão conectados ao sistema.

A partir de todo este cenário, deve-se procurar maneiras de se reduzir as contas, mas reduzir de maneira consciente afim de preservar as atividades já desenvolvidas. Foi observado que existe um grande potencial de redução de energia elétrica a partir do uso consciente e efetivo na iluminação, e as lâmpadas representam o terceiro maior equipamento consumidor de energia elétrica no Brasil.

Por todo o exposto, o presente trabalho analisará o impacto da inserção de lâmpadas de diodo emissor, popularmente conhecidas por LED’s, na Universidade Federal Rural do Semiárido. A análise partirá do pressuposto que além do retorno financeiro, uma boa iluminação é primordial para o bom desenvolvimento de qualquer trabalho. Vale ressaltar que a atual iluminação da Universidade é primordialmente composta por lâmpadas fluorescentes tubulares, e estas lâmpadas já são consideradas tecnologicamente ultrapassadas.

\section{ILUMINAÇÃO EM PRÉDIOS PÚBLICOS NO BRASIL}

No Brasil, debate-se iluminação em prédios públicos há anos, pois este é um assunto comum a todos os cidadãos do país, já que estes prédios funcionam através de impostos pagos pela população. Segundo o [1], no ano de 2018 aproximadamente 7\% de toda a energia produzida no Brasil foi consumida pelo poder público, o que dá cerca de 44,58 TWh, sendo maior parte para manutenção de prédios públicos.

A iluminação representa cerca de $1 / 3$ de todo o gasto com energia elétrica em um prédio. Como as lâmpadas utilizadas em prédios do poder público possuem tecnologia obsoleta, tendo assim uma baixa eficiência, as mesmas acabam por não gerar iluminação adequada para o ambiente e consomem bastante energia elétrica.

Devido à crise econômica que o país atravessa nos últimos anos, os recursos para a atualização e alteração dos serviços são escassos. A modernização de algum serviço só é feita quando a mesma possui uma alta necessidade e ainda assim, precisará de estudos que comprove o seu retorno, que necessita ser econômico ou de bens sociais para a população.

Segundo [2], uma gestão eficiente da iluminação pública e dos prédios públicos pode reduzir em $30 \%$ o valor da conta de energia elétrica de um município, o que seria necessário colocar em prática, visto que a energia elétrica é a segunda maior despesa dos municípios brasileiros. Nos pequenos municípios, de acordo com o [2], além da falta de recursos financeiros também faltam recursos humanos, portanto, a redução dos gastos torna-se indispensável.

Atrelando os dados apresentados ao retorno financeiro, a modernização da iluminação de prédios públicos resulta numa melhora significativa da iluminação e assim, os profissionais que trabalham nestes locais, podem desempenhar com mais eficiência e rapidez suas funções. Sendo essa uma mudança necessária, pelo impacto que resultará para a população. Haverá uma melhora nos serviços disponibilizados aos cidadãos, pois os servidores cometerão menos erros e os processos serão agilizados, já que quando existe uma melhora na iluminação, existe também um aumento na eficiência das tarefas executadas.

\subsection{Lâmpadas de LED}

De acordo com [8], LED's são componentes semicondutores que têm a propriedade de transformar energia elétrica em luz. A luz gerada pelos Leds é originada através do aquecimento destes semicondutores por uma pequena corrente elétrica, gerando uma luz bastante intensa. Os LEDs podem ser de baixa $(0,1 \mathrm{~W})$, média $(0,2 \mathrm{~W}$ à $0,5 \mathrm{~W}$ ) e de alta potência (acima de $0,5 \mathrm{~W}$ ). Em geral, os de baixa e média potência são utilizados para sinalização e efeitos decorativos. Os de alta potência já podem ser aplicados em iluminação geral.

As lâmpadas de LED, se destacam por sua eficiência na iluminação e sua durabilidade. Segundo [3], as lâmpadas LED são até $80 \%$ mais econômicas que lâmpadas incandescentes tradicionais, por uma mesma potência, além da sua durabilidade ser equivalente a 15 lâmpadas incandescentes, faz com que o consumidor economize tanto com a troca das lâmpadas quanto com a manutenção. 
[4] relata que o LED é produzido com materiais atóxicos ao meio ambiente, o que faz com que possa ser descartado sem a necessidade de uma destinação e disposição final especiais. As lâmpadas são ecologicamente corretas por não utilizarem materiais tóxicos e utilizarem pouca matéria prima comparada com outras lâmpadas.

Segundo [5], substituir as lâmpadas fluorescentes pelos modelos de LED é uma forma eficiente de reduzir o valor da conta de energia elétrica, especialmente no verão, quando ela tende a ser mais cara pela aplicação da "bandeira vermelha" nas contas de energia ainda em [5], o mesmo relata que mesmo o preço das lâmpadas de LED sendo mais elevados do que o das fluorescentes, o gasto maior na compra é compensado com a redução na conta de luz e com o baixo custo de manutenção, devido à sua maior durabilidade. Ainda vale ressaltar, que as lâmpadas do tipo LED, se apresentam em várias formas e tamanhos e seu uso pode ser empregado em iluminação residencial, industrial, como também utilizada na decoração de ambientes.

\section{MATERIAIS E MÉTODOS}

A Universidade Federal Rural do Semi-Árido (UFERSA) é constituída de quatro campus em quatro cidades, e tais polos estão localizados nas cidades de Mossoró, Angicos, Pau dos Ferros e Caraúbas, todas no Rio Grande do Norte. O maior campus, o central, está localizado na cidade de Mossoró, sendo este dividido em dois lados, Oeste e o Leste. A pesquisa foi concentrada na análise da troca de iluminação de dois prédios da UFERSA Lado Leste, a saber, Biblioteca e prédio Engenharias 1, onde foi verificado que a iluminação destes prédios é majoritariamente composta por lâmpadas fluorescentes.

As Lâmpadas fluorescentes são tecnologicamente obsoletas e pouco eficientes quando comparadas com as lâmpadas do tipo LED. A troca das lâmpadas fluorescentes por lâmpadas LED de cada prédio. Além da parte econômica, a troca das lâmpadas, pode gerar uma melhora significativa na iluminação de cada ambiente, aumentando o conforto visual de cada usuário, de acordo com [6] quando aumenta o nível de iluminação de um ambiente, aumenta eficiência das pessoas em desempenhar suas atividades. A pesquisa contou com a contagem de lâmpadas por tipo e potência; contando também com a medição de iluminação por ambiente através de um luxímetro. A pesquisa foi restrita a estes prédios, pois apesar de outros prédios da UFERSA ainda estarem em processo da troca de lâmpadas fluorescentes por LED, até a finalização deste trabalho, apenas os prédios mencionados, encontravam-se com a troca finalizada. A Tabela 1 mostra a quantidade de lux por ambiente em cada região analisada no prédio de Engenharias 1, como também a quantidade de lâmpadas por ambiente, sua potência e seu tipo, antes da troca das lâmpadas.

Tabela 1: Dados luminotécnicos do prédio de Engenharias 1 (Antes da substituição das lâmpadas).

\begin{tabular}{|c|c|c|c|c|}
\hline Local & Lux médio $(L x)$ & $N^{\circ}$ de Lâmpadas & Potência $(W)$ & Tipo \\
\hline $\begin{array}{c}\text { Lab. De Instalações } \\
\text { e Máquinas }\end{array}$ & 1223 & 36 & 40 & $\begin{array}{c}\text { fluorescente } \\
\text { tubular }\end{array}$ \\
\hline $\begin{array}{l}\text { Lab. De Medição } \\
\text { Elétricas e } \\
\text { Eletricidade Básica }\end{array}$ & 1028 & 36 & 40 & $\begin{array}{c}\text { fluorescente } \\
\text { tubular }\end{array}$ \\
\hline $\begin{array}{l}\text { Lab. De Térmicas e } \\
\text { Metrologia }\end{array}$ & 710 & 24 & 40 & $\begin{array}{c}\text { fluorescente } \\
\text { tubular }\end{array}$ \\
\hline Lab. De Projetos & 938 & 24 & 40 & $\begin{array}{l}\text { fluorescente } \\
\text { tubular }\end{array}$ \\
\hline $\begin{array}{c}\text { Lab. De Ensaios } \\
\text { Mecânicos }\end{array}$ & 423 & 36 & 40 & $\begin{array}{c}\text { fluorescente } \\
\text { tubular }\end{array}$ \\
\hline BWC Feminino & 236 & 4 & 40 & $\begin{array}{c}\text { fluorescente } \\
\text { tubular }\end{array}$ \\
\hline BWC Masculino & 307 & 4 & 40 & $\begin{array}{c}\text { fluorescente } \\
\text { tubular }\end{array}$ \\
\hline $\begin{array}{c}\text { BWC Acessível } \\
\text { Feminino(Depósito) }\end{array}$ & 80 & 1 & 28 & $\begin{array}{c}\text { fluorescente } \\
\text { compacta }\end{array}$ \\
\hline $\begin{array}{c}\text { BWC Acessível } \\
\text { Masculino }\end{array}$ & 90 & 1 & 28 & $\begin{array}{c}\text { fluorescente } \\
\text { compacta }\end{array}$ \\
\hline Coordenação & 482 & 8 & 40 & $\begin{array}{l}\text { fluorescente } \\
\text { tubular }\end{array}$ \\
\hline $\begin{array}{l}\text { Lab. de Energias } \\
\text { Renováveis }\end{array}$ & 734 & 24 & 40 & $\begin{array}{c}\text { fluorescente } \\
\text { tubular }\end{array}$ \\
\hline Lab. De Soldagem & 403 & 48 & 40 & $\begin{array}{c}\text { fluorescente } \\
\text { tubular }\end{array}$ \\
\hline
\end{tabular}




\begin{tabular}{|c|c|c|c|c|}
\hline Lab. De Eletrônica & 1057 & 36 & 40 & $\begin{array}{l}\text { fluorescente } \\
\text { tubular }\end{array}$ \\
\hline $\begin{array}{l}\text { Lab. Produção } \\
\text { Mecânica }\end{array}$ & 982 & 48 & 40 & $\begin{array}{l}\text { fluorescente } \\
\text { tubular }\end{array}$ \\
\hline $\begin{array}{l}\text { Lab. De Automação } \\
\text { e Controle }\end{array}$ & 1035 & 36 & 40 & $\begin{array}{l}\text { fluorescente } \\
\text { tubular }\end{array}$ \\
\hline Corredores & 134 & 24 & 40 & $\begin{array}{c}\text { fluorescente } \\
\text { tubular }\end{array}$ \\
\hline Área Externa & - & 5 & - & $\begin{array}{l}\text { refletores - vapor } \\
\text { de mercúrio }\end{array}$ \\
\hline $\begin{array}{c}\text { Corredores de } \\
\text { BWC }\end{array}$ & 142 & 3 & 28 & $\begin{array}{c}\text { fluorescente } \\
\text { compacta }\end{array}$ \\
\hline
\end{tabular}

Fonte: [7]

Como mostrado na Tabela 1, foram analisadas 398 lâmpadas em 18 ambientes, sendo 393 lâmpadas fluorescentes e 5 vapores de mercúrio. Do total analisado 57 lâmpadas encontravam-se com defeito, no caso, queimadas, onde este número impactou diretamente na perda da qualidade de iluminação de alguns ambientes, pois as lâmpadas queimadas fazem com que o nível de iluminação do ambiente reduzia relativamente, visto que na maioria destes ambientes a iluminação natural não é suficiente. A Tabela 2, mostra a quantidade de lux por ambiente em cada região analisada no prédio da Biblioteca, como também a quantidade de lâmpadas por ambiente, sua potência e seu tipo, antes da troca das lâmpadas.

Tabela 2: Dados luminotécnicos do prédio da Biblioteca (antes da substituição das lâmpadas).

\begin{tabular}{|c|c|c|c|c|}
\hline Local & Lux médio $(L x)$ & $N^{\circ}$ de Lâmpadas & Potência $(W)$ & Tipo \\
\hline Guarda Volume & 776 & 12 & 40 & $\begin{array}{l}\text { fluorescente } \\
\text { tubular }\end{array}$ \\
\hline Hall de Entrada & 121 & 8 & 40 & $\begin{array}{l}\text { fluorescente } \\
\text { tubular }\end{array}$ \\
\hline $\begin{array}{l}\text { Devolução e } \\
\text { Renovação }\end{array}$ & 554 & 12 & 40 & $\begin{array}{l}\text { fluorescente } \\
\text { tubular }\end{array}$ \\
\hline Direção & 250 & 4 & 40 & $\begin{array}{l}\text { fluorescente } \\
\text { tubular }\end{array}$ \\
\hline Coordenação & 150 & 4 & 40 & $\begin{array}{l}\text { fluorescente } \\
\text { tubular }\end{array}$ \\
\hline Espaço Digital & 345 & 36 & 40 & $\begin{array}{l}\text { fluorescente } \\
\text { tubular }\end{array}$ \\
\hline $\begin{array}{l}\text { Área de Estudo Em } \\
\text { Grupo }\end{array}$ & 243 & 30 & 40 & $\begin{array}{l}\text { fluorescente } \\
\text { tubular }\end{array}$ \\
\hline Acervo de Livros & 190 & 48 & 40 & $\begin{array}{l}\text { fluorescente } \\
\text { tubular }\end{array}$ \\
\hline $\begin{array}{l}\text { Área de Estudo } \\
\text { Individual }\end{array}$ & 85 & 48 & 40 & $\begin{array}{l}\text { fluorescente } \\
\text { tubular }\end{array}$ \\
\hline $\begin{array}{c}\text { Setor de } \\
\text { Informação e } \\
\text { Referência }\end{array}$ & 289 & 4 & 36 & $\begin{array}{l}\text { fluorescente } \\
\text { tubular }\end{array}$ \\
\hline $\begin{array}{l}\text { Banheiro do Setor } \\
\text { de Informação }\end{array}$ & 215 & 2 & 36 & $\begin{array}{l}\text { fluorescente } \\
\text { tubular }\end{array}$ \\
\hline Sala de Arquivo & 200 & 2 & 40 & $\begin{array}{l}\text { fluorescente } \\
\text { tubular }\end{array}$ \\
\hline Auditório & 180 & 16 & 40 & $\begin{array}{l}\text { fluorescente } \\
\text { tubular }\end{array}$ \\
\hline Fotocópia & 150 & 2 & 40 & $\begin{array}{l}\text { fluorescente } \\
\text { tubular }\end{array}$ \\
\hline Escada do Pátio & 330 & 8 & $6 \times 40 W$ e $2 \times 20 W$ & $\begin{array}{l}\text { fluorescente } \\
\text { tubular }\end{array}$ \\
\hline Anexo de Coleções & 321 & 12 & 40 & $\begin{array}{l}\text { fluorescente } \\
\text { tubular }\end{array}$ \\
\hline $\begin{array}{c}\text { Corredor de } \\
\text { Processo Técnico }\end{array}$ & - & 4 & 40 & $\begin{array}{c}\text { fluorescente } \\
\text { tubular }\end{array}$ \\
\hline
\end{tabular}




\begin{tabular}{|c|c|c|c|c|}
\hline Processo Técnico & 273 & 12 & 40 & $\begin{array}{l}\text { fluorescente } \\
\text { tubular }\end{array}$ \\
\hline Sipaq & 163 & 4 & 40 & $\begin{array}{l}\text { fluorescente } \\
\text { tubular }\end{array}$ \\
\hline Restauração & 247 & 4 & 40 & $\begin{array}{l}\text { fluorescente } \\
\text { tubular }\end{array}$ \\
\hline Copa & 309 & 4 & 40 & $\begin{array}{l}\text { fluorescente } \\
\text { tubular }\end{array}$ \\
\hline $\begin{array}{l}\text { Corredor do } \\
\text { Banheiro }\end{array}$ & 601 & 2 & 40 & $\begin{array}{l}\text { fluorescente } \\
\text { tubular }\end{array}$ \\
\hline Banheiro & 354 & 4 & 40 & $\begin{array}{l}\text { fluorescente } \\
\text { tubular }\end{array}$ \\
\hline Escada & 38 & 3 & 16 & $\begin{array}{c}\text { compacta } \\
\text { fluorescente }\end{array}$ \\
\hline Saída Para Escada & 138 & 4 & 40 & $\begin{array}{l}\text { fluorescente } \\
\text { tubular }\end{array}$ \\
\hline $\begin{array}{c}\text { Área de Estudo } \\
\text { Coletivo }\end{array}$ & 300 & 104 & 40 & $\begin{array}{l}\text { fluorescente } \\
\text { tubular }\end{array}$ \\
\hline Sala em Grupo 1 & 430 & 2 & 40 & $\begin{array}{l}\text { fluorescente } \\
\text { tubular }\end{array}$ \\
\hline Sala em Grupo 2 & 400 & 2 & 40 & $\begin{array}{l}\text { fluorescente } \\
\text { tubular }\end{array}$ \\
\hline Sala em Grupo 3 & 380 & 2 & 40 & $\begin{array}{l}\text { fluorescente } \\
\text { tubular }\end{array}$ \\
\hline Sala em Grupo 4 & 325 & 2 & 40 & $\begin{array}{l}\text { fluorescente } \\
\text { tubular }\end{array}$ \\
\hline Sala em Grupo 5 & 450 & 2 & 40 & $\begin{array}{l}\text { fluorescente } \\
\text { tubular }\end{array}$ \\
\hline Sala em Grupo 6 & 320 & 2 & 40 & $\begin{array}{l}\text { fluorescente } \\
\text { tubular }\end{array}$ \\
\hline Sala em Grupo 7 & 441 & 2 & 40 & $\begin{array}{l}\text { fluorescente } \\
\text { tubular }\end{array}$ \\
\hline Sala em Grupo 8 & 380 & 2 & 40 & $\begin{array}{l}\text { fluorescente } \\
\text { tubular }\end{array}$ \\
\hline Sala em Grupo 9 & 398 & 2 & 40 & $\begin{array}{l}\text { fluorescente } \\
\text { tubular }\end{array}$ \\
\hline $\begin{array}{l}\text { Banheiro } \\
\text { Masculino }\end{array}$ & 159 & 8 & 20 & $\begin{array}{l}\text { fluorescente } \\
\text { tubular }\end{array}$ \\
\hline Banheiro Feminino & 54 & 12 & 40 & $\begin{array}{l}\text { fluorescente } \\
\text { tubular }\end{array}$ \\
\hline $\begin{array}{l}\text { Corredor do } \\
\text { Banheiro }\end{array}$ & 230 & 4 & 40 & $\begin{array}{l}\text { fluorescente } \\
\text { tubular }\end{array}$ \\
\hline $\begin{array}{l}\text { Sala de Estudo } \\
\text { Individual (Em } \\
\text { Desuso) }\end{array}$ & - & 18 & 40 & $\begin{array}{l}\text { fluorescente } \\
\text { tubular }\end{array}$ \\
\hline $\begin{array}{c}\text { Sala de Estudo } \\
\text { Individual }\end{array}$ & 116 & 20 & 40 & $\begin{array}{l}\text { fluorescente } \\
\text { tubular }\end{array}$ \\
\hline $\begin{array}{l}\text { Área de Estudo } \\
\text { Coletivo } 2\end{array}$ & 441 & 22 & 40 & $\begin{array}{l}\text { fluorescente } \\
\text { tubular }\end{array}$ \\
\hline $\begin{array}{l}\text { Varanda da Área } \\
\text { De Estudo Coletivo } \\
2\end{array}$ & 30 & 3 & - & $\begin{array}{l}\text { refletores - vapor } \\
\text { de mercúrio }\end{array}$ \\
\hline $\begin{array}{c}\text { Escada da Parte do } \\
\text { Pátio }\end{array}$ & 350 & 13 & $\begin{array}{c}10 \mathrm{x} 40 \mathrm{~W} \text { e } \\
3 \times 20 \mathrm{~W}\end{array}$ & $\begin{array}{l}\text { fluorescente } \\
\text { tubular }\end{array}$ \\
\hline
\end{tabular}

Fonte: [7]

Através da Tabela 2, observa-se que a biblioteca dos 43 ambientes, possui 511 lâmpadas, sendo 507 lâmpadas fluorescentes e 3 refletores de vapor de mercúrio. Do total, 72 lâmpadas apresentaram defeitos (queimadas). Assim, como mencionado anteriormente, este fator reduz a qualidade de iluminação do ambiente e que de acordo com [6] diminui a eficiência das atividades desenvolvidas. 
Finalizadas as etapas de medição, contagem e verificação das lâmpadas dos dois prédios, constatou-se que o tipo mais comum de lâmpada utilizado foi a lâmpada Fluorescente tubular de 40W. No prédio de Engenharias 1, por exemplo, das 398 lâmpadas dos ambientes, 388 são lâmpadas fluorescentes de 40W e no prédio da Biblioteca das 511 lâmpadas, 492 são fluorescentes de 40W.Por esta razão, as lâmpadas de LED adquiridas pela Universidade foram lâmpadas equivalentes às fluorescentes de $40 \mathrm{w}$. A Tabela 3 apresenta a comparação das características das lâmpadas fluorescentes de 40W com as lâmpadas LED de 18W, que será implementada.

Tabela 3: Dados técnicos das lâmpadas que vão ser inseridas nos prédios da Biblioteca e Engenharias 1.

\begin{tabular}{ccc}
\hline Tipo & Potência $(w)$ & $\begin{array}{c}\text { Fluxo Luminoso } \\
(\text { lm })\end{array}$ \\
\hline $\begin{array}{c}\text { Fluorescente } \\
\text { Tubular }\end{array}$ & 40 & 2500 \\
LED Tubular & 18 & 2100 \\
\hline
\end{tabular}

Fonte: [7]

Como mostrado na Tabela 3, as lâmpadas possuem potências diferentes, sendo a fluorescente 2x mais potente que a LED, mas apresentam fluxo luminoso aproximado. A lâmpada LED é então mais eficiente que a lâmpada fluorescente, pois consegue iluminar de forma equivalente gastando 55\% menos energia, o que se torna visivelmente vantajoso economicamente para a Universidade.

\section{RESULTADOS}

\subsection{Troca lâmpadas Prédio Engenharias 1}

Após a troca das lâmpadas do tipo fluorescente pôr do tipo LED, foram realizadas novas medições com o luxímetro, para coletar os dados da nova iluminação. Vale ressaltar que conforme mostrado na Tabela 1, esse prédio possui 18 ambientes e apenas 14 foram analisados, pois os ambientes: área externa, corredor bwc, banheiro acessível masculino e feminino não foram contemplados com a troca da iluminação, por incompatibilidade das luminárias com as lâmpadas adquiridas. A Tabela 4, mostra a variação dos níveis de iluminação, antes e depois da troca por LED do prédio de Engenharias 1.

Tabela 4: Comparação entre os níveis de iluminação do prédio de Engenharias 1

(antes e após a troca das lâmpadas)

\begin{tabular}{|c|c|c|}
\hline Região & $\begin{array}{l}\text { Iluminação } \\
\text { antiga }(l x)\end{array}$ & $\begin{array}{c}\text { Iluminação nova } \\
\text { (lx) }\end{array}$ \\
\hline Lab. de Metrologia & 710 & 914 \\
\hline $\begin{array}{l}\text { Lab. de Ensaios } \\
\text { Mecânicos }\end{array}$ & 423 & 908 \\
\hline BWC Feminino & 236 & 310 \\
\hline BWC Masculino & 307 & 320 \\
\hline $\begin{array}{l}\text { Lab. de Motores e } \\
\text { Máquinas }\end{array}$ & 1223 & 926 \\
\hline Coordenação & 482 & 700 \\
\hline Lab. de Soldagem & 403 & 903 \\
\hline $\begin{array}{l}\text { Lab. de Produção } \\
\text { Mecânica }\end{array}$ & 782 & 1002 \\
\hline $\begin{array}{l}\text { Lab. de Energias } \\
\text { Renováveis }\end{array}$ & 734 & 1056 \\
\hline Lab. de Eletrônica & 1057 & 1116 \\
\hline $\begin{array}{l}\text { Lab. Controle e } \\
\text { Automação }\end{array}$ & 1035 & 1000 \\
\hline Corredor & 134 & 220 \\
\hline $\begin{array}{c}\text { Lab. de Eletricidade } \\
\text { Básica }\end{array}$ & 1028 & 1120 \\
\hline
\end{tabular}

Fonte: [7] 
De acordo com a Tabela 4, os ambientes onde tiveram a maior variação na iluminância, foram os Laboratórios de Ensaios Mecânicos e Soldagens, que tinham respectivamente, 11 e 14 lâmpadas queimadas, um número bastante elevado, que prejudicava bastante as atividades desenvolvidas pelos profissionais que utilizam estes espaços.

A partir das novas medições foi consultada [8], para verificar se os níveis da nova iluminação estavam de acordo com os recomendados pela Norma. A Tabela 5 compara os níveis de iluminação medido com o mínimo descrito em Norma, no prédio de Engenharias 1.

Tabela 5: Comparação entre níveis de iluminação medido e o recomendado pela NBR 8995 no prédio de Engenharias 1.

\begin{tabular}{cccc}
\hline Região & $\begin{array}{c}\text { Iluminação } \\
\text { antiga }(l x)\end{array}$ & $\begin{array}{c}\text { Iluminação nova } \\
(l x)\end{array}$ & $\begin{array}{c}\text { Lux Mínimo de } \\
\text { acordo com } a \\
\text { NBR } 8995(l x)\end{array}$ \\
\hline $\begin{array}{c}\text { Lab. de Metrologia } \\
\text { Lab. de Ensaios }\end{array}$ & 710 & 914 & 500 \\
Mecânicos & 423 & 908 & 500 \\
BWC Feminino & 236 & 310 & 500 \\
BWC Masculino & 307 & 320 & 500 \\
Lab. de Motores e & 1223 & 926 & 200 \\
Máquinas & 482 & 700 & 200 \\
Coordenação & 403 & 903 & 500 \\
Lab. de Soldagem & 782 & 1002 & 500 \\
Lab. de Produção & & 1056 & 500 \\
Mecânica & 734 & 1116 & 500 \\
Lab. de Energias & 1057 & 1000 & 500 \\
Renováveis & 1035 & 220 & 100 \\
Lab. de Eletrônica & 134 & 1120 & 500 \\
Lab. Controle e & 1028 & & \\
Automação & & & \\
Corredor & Lab. de Eletricidade & Básica &
\end{tabular}

Fonte: [7]

De acordo com a Tabela 5, é possível comprovar que os níveis de iluminação aumentaram de maneira significativa em todos os ambientes, atendendo ainda assim aos requisitos mínimos exigidos pela norma, desta forma as atividades desenvolvidas neste prédio se darão de forma mais eficiente.

Visando complementar a análise e verificar o grau de satisfação dos usuários após a substituição das lâmpadas, foi realizada uma pesquisa de satisfação (através de questionário), obtendo retorno de 30 estudantes e servidores, sendo 28 estudantes e 2 servidores, que utilizam de alguma forma os ambientes contemplados pelo prédio de Engenharias 1, para desempenharem suas funções, sejam elas profissionais ou de estudo. A pesquisa iniciada no dia 05 de julho de 2019, ficou disponível até o dia 26 de julho de 2019, teve o principal intuito, de analisar por meio das pessoas que lá frequentam, a qualidade da mudança da iluminação e a satisfação destas com a nova iluminação. A Figura 1, representa a frequência das pessoas que utilizam o prédio de Engenharias 1. O gráfico foi divido em três níveis de frequência, sendo eles, frequente, moderado ou raramente frequenta o prédio. 


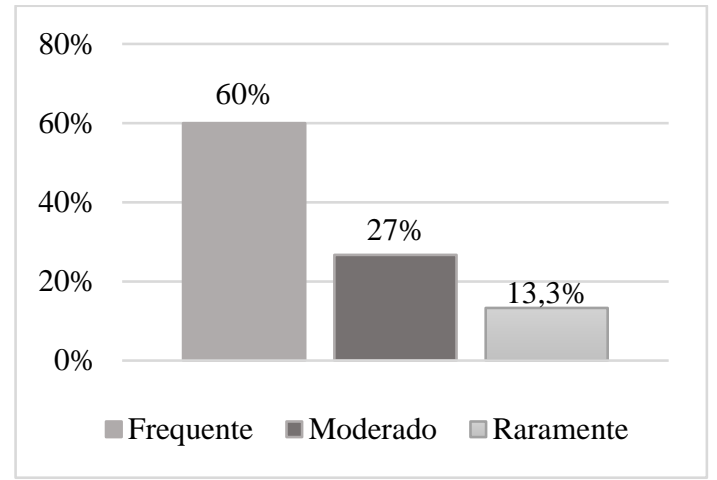

Figura1. Frequência de utilização do prédio de Engenharias 1.

Fonte: [7]

Como mostra a Figura 1, a maior parte das pessoas que realizaram a pesquisa, ou seja $60 \%$, utilizam o prédio frequentemente. Dentre os entrevistados, as pessoas que mais frequentam o prédio de Engenharias 1, são as que sofrem o maior impacto com a mudança da iluminação, por tanto a opinião destas é a mais importante. Dando continuando a análise dos resultados, 60\% das pessoas perceberam a mudança da iluminação do prédio de Engenharias 1, e $40 \%$ não perceberam.

Os dados apresentados anteriormente, estão diretamente conectados à Figura 1, pois a porcentagem de pessoas que perceberam a mudança da iluminação, no caso, $60 \%$, obteve o mesmo percentual das pessoas que fazem uso frequente do prédio, isto indica que as pessoas que tem um contato maior com este local estão propensas a perceberem mais os impactos de quaisquer alterações no prédio, neste caso foi a mudança da iluminação. Uma das perguntas do questionário visava analisar o nível de satisfação dos usuários com a mudança da iluminação do tipo fluorescente pôr do tipo LED. Observou-se que $75 \%$ disseram estar satisfeitos com a mudança da iluminação, e os demais $25 \%$ disseram não achar satisfatória essa. Levou-se em consideração apenas as pessoas que perceberam que houve mudança na iluminação após a troca das lâmpadas.

A Figura 3 mostra que o nível de satisfação das pessoas com a mudança da iluminação se deu de forma satisfatória, onde $75 \%$ das pessoas que perceberam a mudança ficaram satisfeitas, comprovando também que nova iluminação está adequada com os níveis requeridos por [8].

Das 398 lâmpadas analisadas, 388 foram substituídas por lâmpadas LED, ou seja, a mudança contemplou 97,4\% das lâmpadas. A potência de iluminação instalada inicialmente era de 15,66 kW, e após a mudança (troca) reduziu para $7,04 \mathrm{~kW}$, tendo uma redução de aproximadamente $55 \%$ da potência de iluminação instalada. Foi feita uma previsão em relação à potência de iluminação economizada, e esse percentual poderá gerar uma economia mensal de $\mathrm{R} \$ 430$ [9].

\subsection{Troca lâmpadas Prédio Biblioteca}

O prédio da Biblioteca passou por análise similar ao prédio de Engenharias 1, onde foram realizadas as medições e comparadas aos valores de iluminação antes e depois da mudança do tipo de iluminação.

A mudança dos 43 ambientes, só não abrangeu 4 ambientes sendo estes: as escadas, varanda da área de estudo coletivo e a sala de estudo individual. Esses ambientes listados apresentaram luminárias incompatíveis com o modelo adquirido e por este motivo não foram contemplados com a mudança. Foi realizada uma homogeneização dos ambientes, onde 6 ambientes que tinham sido analisados inicialmente separados, foram analisados juntos, como sendo um único ambiente, devido desempenharem as mesmas funções e estarem aglutinados. A Tabela 6, mostra a variação dos níveis de iluminação dos 33 ambientes analisados, antes e depois da mudança das lâmpadas do tipo fluorescente por lâmpadas LED no prédio da Biblioteca.

Tabela 6. Comparação entre os níveis de iluminação da Biblioteca

\begin{tabular}{ccc}
\hline Local & $\begin{array}{c}\text { Iluminação } \\
\text { antiga }(l x)\end{array}$ & $\begin{array}{c}\text { Iluminação nova } \\
(l x)\end{array}$ \\
\hline Guarda Volume & 776 & 560 \\
Entrada & 121 & 430 \\
Devolução e & 554 & 540 \\
Renovação & 250 & 315 \\
Direção & &
\end{tabular}




\begin{tabular}{|c|c|c|}
\hline Coordenação & 150 & 312 \\
\hline Espaço Digital & 345 & 360 \\
\hline $\begin{array}{c}\text { Área de Estudo Em } \\
\text { Grupo }\end{array}$ & 243 & 356 \\
\hline Acervo de Livros & 190 & 360 \\
\hline $\begin{array}{c}\text { Área de Estudo } \\
\text { Individual } \\
\text { Setor de }\end{array}$ & 85 & 320 \\
\hline $\begin{array}{l}\text { Informação e } \\
\text { Referência }\end{array}$ & 289 & 310 \\
\hline Auditório & 180 & 306 \\
\hline Fotocópia & 150 & 460 \\
\hline Anexo de Coleções & 321 & 330 \\
\hline Processo Técnico & 273 & 315 \\
\hline Sipaq & 163 & 296 \\
\hline Restauração & 247 & 308 \\
\hline Copa & 309 & 316 \\
\hline Banheiro & 354 & 380 \\
\hline $\begin{array}{l}\text { Área de Estudo } \\
\text { Coletivo }\end{array}$ & 300 & 430 \\
\hline Sala em Grupo 1 & 430 & 560 \\
\hline Sala em Grupo 2 & 400 & 590 \\
\hline Sala em Grupo 3 & 380 & 520 \\
\hline Sala em Grupo 4 & 325 & 460 \\
\hline Sala em Grupo 5 & 450 & 550 \\
\hline Sala em Grupo 6 & 320 & 530 \\
\hline Sala em Grupo 7 & 441 & 520 \\
\hline Sala em Grupo 8 & 380 & 500 \\
\hline Sala em Grupo 9 & 398 & 460 \\
\hline $\begin{array}{c}\text { Banheiro } \\
\text { Masculino }\end{array}$ & 159 & 330 \\
\hline Banheiro Feminino & 54 & 320 \\
\hline $\begin{array}{l}\text { Corredor do } \\
\text { Banheiro }\end{array}$ & 230 & 280 \\
\hline $\begin{array}{l}\text { Sala de Estudo } \\
\text { Individual }\end{array}$ & 116 & 500 \\
\hline $\begin{array}{l}\text { Área de Estudo } \\
\text { Coletivo } 2\end{array}$ & 441 & 560 \\
\hline
\end{tabular}

Fonte: [7]

A partir das novas medições, mostradas na Tabela 6, consultou-se [8], para verificar se os níveis da nova iluminação estão atendendo às exigências referidas pela Norma. A Tabela 7, compara os níveis de iluminação medidos no prédio da Biblioteca antes e após a substituição das lâmpadas com o mínimo descrito em Norma.

Tabela 7. Comparação entre níveis de iluminação medido e o recomendado pela NBR na Biblioteca.

\begin{tabular}{cccc}
\hline Local & $\begin{array}{c}\text { Iluminação } \\
\text { antiga }(l x)\end{array}$ & $\begin{array}{c}\text { Iluminação nova } \\
(l x)\end{array}$ & $\begin{array}{c}\text { Lux Mínimo de } \\
\text { acordo com } a \\
\text { NBR } 8995(l x)\end{array}$ \\
\hline Guarda Volume & 776 & 560 & 200 \\
Entrada & 121 & 430 & 300 \\
Devolução e & 554 & 540 & 500 \\
Renovação & 250 & 315 & 500 \\
$\quad$ Direção & 150 & 312 & 500 \\
Coordenação & 345 & 360 & 500 \\
Espaço Digital & 243 & 356 & 500 \\
Área de Estudo Em & 190 & 360 & 200 \\
Grupo & 85 & 320 & 500 \\
Acervo de Livros & Área de Estudo & & \\
Individual & & &
\end{tabular}




\begin{tabular}{|c|c|c|c|}
\hline $\begin{array}{c}\text { Setor de } \\
\text { Informação e } \\
\text { Referência }\end{array}$ & 289 & 310 & 500 \\
\hline Auditório & 180 & 306 & 200 \\
\hline Fotocópia & 150 & 460 & 200 \\
\hline Anexo de Coleções & 321 & 330 & 200 \\
\hline Processo Técnico & 273 & 315 & 500 \\
\hline Sipaq & 163 & 296 & 500 \\
\hline Restauração & 247 & 308 & 200 \\
\hline Copa & 309 & 316 & 200 \\
\hline Banheiro & 354 & 380 & 200 \\
\hline $\begin{array}{l}\text { Área de Estudo } \\
\text { Coletivo }\end{array}$ & 300 & 430 & 500 \\
\hline Sala em Grupo 1 & 430 & 560 & 500 \\
\hline Sala em Grupo 2 & 400 & 590 & 500 \\
\hline Sala em Grupo 3 & 380 & 520 & 500 \\
\hline Sala em Grupo 4 & 325 & 460 & 500 \\
\hline Sala em Grupo 5 & 450 & 550 & 500 \\
\hline Sala em Grupo 6 & 320 & 530 & 500 \\
\hline Sala em Grupo 7 & 441 & 520 & 500 \\
\hline Sala em Grupo 8 & 380 & 500 & 500 \\
\hline Sala em Grupo 9 & 398 & 460 & 500 \\
\hline $\begin{array}{c}\text { Banheiro } \\
\text { Masculino }\end{array}$ & 159 & 330 & 200 \\
\hline Banheiro Feminino & 54 & 320 & 200 \\
\hline $\begin{array}{l}\text { Corredor do } \\
\text { Banheiro }\end{array}$ & 230 & 280 & 100 \\
\hline $\begin{array}{l}\text { Sala de Estudo } \\
\text { Individual }\end{array}$ & 116 & 500 & 500 \\
\hline $\begin{array}{l}\text { Área de Estudo } \\
\text { Coletivo } 2\end{array}$ & 441 & 560 & 500 \\
\hline
\end{tabular}

Fonte: [7]

Conforme mostra a Tabela 7, a troca das lâmpadas melhorou consideravelmente a iluminação, porém em alguns ambientes a substituição ainda não foi suficiente para atingir os valores recomendados por [8]. Segundo [8], os ambientes direção, coordenação, espaço digital, área de estudos em grupo e área de estudo individual não atingiram os valores mínimos recomendados.

Assim como no prédio Engenharias 1, após a verificação da troca de iluminação foi realizada uma pesquisa, análoga a que foi realizada no prédio de Engenharias 1, com servidores e estudantes que frequentam à Biblioteca para verificar a partir da percepção deles a qualidade da nova iluminação. A pesquisa contou com 103 respostas, destas respostas 96 foram de estudantes e 7 foram de servidores, a pesquisa foi iniciada no dia 05 de julho de 2019 e ficou disponível até o dia 30 de julho de 2019.

Contabilizou-se que a frequência das pessoas que utilizam o prédio da Biblioteca . e para efeito de melhor avaliação, essa etapa foi dividida em três níveis de frequência semanal, sendo eles frequente ( 7 a 5 vezes por semana), moderado ( 3 a 4 vezes por semana) ou raramente ( 2 ou 1 vez por semana ou menos isso) que vai à Biblioteca. Nesta etapa foi estabelecida uma escala semanal de uso, por ser um ambiente que possui muita rotatividade e um fluxo maior de pessoas, porém o seu uso é mais acentuado em período próximo às avaliações semestrais. Os resultados mostraram que $32 \%$ fazem uso frequente do prédio, $26 \%$ de forma moderada e $42 \%$ raramente frequentam.

É importante mencionar, que as pessoas que se encaixaram no grupo "raramente frequentam", os $42 \%$, ainda assim tem uma frequência elevada, pois são geralmente os estudantes que utilizam a biblioteca para estudos apenas nos finais de semana por terem aulas e outras obrigações durante a semana.

Dando continuidade à aplicação do questionário, avaliou-se que $45 \%$ das pessoas perceberam a mudança da iluminação da Biblioteca após a substituição das lâmpadas, e os outros 55\% não perceberam. Essa quantidade maior de pessoas que não perceberam a troca de lâmpadas, provavelmente deve-se ao fato do maior número de pessoas utilizarem a biblioteca apenas nos finais de semana, que de acordo com o informado anteriormente, representaram $42 \%$. Vale ressaltar que o prédio da biblioteca tem suas atividades reduzidas nos finais de semana, onde só funciona o pavimento superior de 7:00 às 20:00, diferentemente do restante da 
semana (segunda a sexta) que funciona os dois pavimentos, onde o superior é 24 horas por dia e o inferior é de 7:00 às 22:00. Nos finais de semana, é utilizado na maior parte do tempo a iluminação natural, e a iluminação mista (natural e artificial) o que dificulta a percepção da mudança da iluminação nestes casos.

Para visualizar o nível de satisfação com a mudança da iluminação, a Figura 2 apresenta estes dados. Este gráfico levou em consideração apenas as pessoas que perceberam a mudança da iluminação onde avaliou-se os seguintes níveis de satisfação: satisfatório, não satisfatório e indiferente, porém algumas pessoas deram outras respostas que não condiziam com a pergunta e foi adicionado a pesquisa no nível "outros".

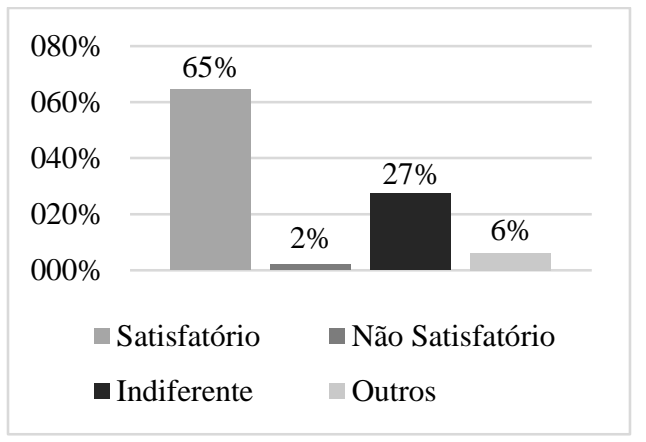

Figura 2. Satisfação com a mudança da iluminação do prédio da Biblioteca.

\section{Fonte: [7]}

Através da Figura 2 foi possível verificar o nível de satisfação das pessoas com a mudança da iluminação, onde percebe-se que a maioria das pessoas (já mencionado anteriormente, em torno de 45\%), que perceberam a mudança, e consideraram satisfatória mesmo a iluminação em alguns locais ainda estando fora dos níveis adequados por [8].

Das 511 lâmpadas analisadas na biblioteca, 474 foram substituídas por LED, ou seja, a mudança contemplou 92,7\% das lâmpadas do prédio. Reduzindo a potência de iluminação instalada que era de 19,268 $\mathrm{kW}$ para $8,84 \mathrm{~kW}$, tendo uma redução de carga equivalente a $54 \%$. Foi estimado o quanto esta carga geraria de economia mensal para o prédio da biblioteca, e o valor encontrado foi de R \$ 2100 [9].

\section{CONCLUSÃO}

Nas inspeções feitas, foram analisados 61 ambientes, com 909 lâmpadas, deste total 862 lâmpadas com tecnologia obsoletas foram substituídas por LED. As novas lâmpadas, de LED possuem uma maior eficiência de iluminação do que as fluorescentes lá estavam. Afim de comprovar empiricamente a sua eficácia foram realizadas medições, para avaliar a mudança os níveis de iluminação, com a alteração da iluminação, os dados gerados e analisados comprovaram que esta mudança acarretou na melhoria significativa da qualidade de iluminação da Universidade, nos prédios analisados.

Mesmo com a mudança de valores de iluminação, foi preciso realizar a pesquisa de satisfação para relatar se a mudança teve o seu objetivo concretizado, que seria a melhoria da qualidade. A mesma pôde comprovar que a nova iluminação foi majoritariamente aceita pelas pessoas que frequentam os prédios analisados. Sendo o parâmetro mais relevante, as pessoas que passam mais tempo nestes ambientes, ou seja, os funcionários destes locais, relataram que houve uma melhoria visual significativa, onde os que trabalhavam com a parte administrativa foram os que mais ficaram satisfeitos por terem a necessidade de uma boa iluminação para poder efetuar suas tarefas.

Os níveis de iluminação foram melhorados de maneira expressiva, comprovando assim, o aumento na iluminação dos prédios. Com o auxílio [8], foi verificado que mesmo com o aumento dos níveis de iluminação, em alguns ambientes os níveis mínimos descritos em norma não foram atingidos. Nestes casos, é necessário um aumento dos níveis de iluminação com a inserção de mais lâmpadas. Sugere-se a realização de um diagnóstico energético mais aprofundado para indicar onde deverão ocorrer ajustes.

Além da qualidade da iluminação, a mudança trouxe também uma redução de custos significativa, em cada prédio analisado. Sendo este um ponto muito importante, para a Universidade, vide o contexto onde ela está inserida, de contingenciamentos e cortes. A mesma, passa por dificuldades no pagamento das despesas de manutenção. A iluminação é uma despesa essencial para o funcionamento de qualquer instituição, e a partir desta conjuntura, foi analisado que a economia mensal dos dois prédios pode chegar a $\mathrm{R} \$ 2500$, tendo ainda a possibilidade deste valor crescer. A redução viabiliza a aplicação desta mudança em outros prédios da 
Universidade, visto que esta economia é permanente e gradativa, ou seja, quanto mais tempo passar maior será o valor poupado, ajudando-a na redução de despesas necessárias. A UFERSA assim poderá atravessar este período de redução do orçamento com o menor impacto possível em suas atividades.

\section{REFERÊNCIAS}

[1] BRASIL. Empresa de Pesquisa Energética. Ministério de Minas e Energia (Org.). Balanço Energético Nacional 2019. 2019. Disponível em: <http://epe.gov.br/pt/publicacoes-dadosabertos/publicacoes/balanco-energetico-nacional-2019>. Acesso em: 27 jul. 2019.

[2] PROCEL, Programa Nacional de Conservação de Energia Elétrica. Disponivel em: <http://www.procelinfo.com.br/main.asp?ViewID=\%7B8D1AC2E8-F790-4B7E-8DDD-

$\mathrm{CAF} 4 \mathrm{CDD} 2 \mathrm{BC} 34 \% 7 \mathrm{D} \&$ params $=\mathrm{itemID}=\%$ 7BBF0A4E12-6527-48DA-8321-

2F24AA15DB1F\%7D;\&UIPartUID=\%7BD90F22DB-05D4-4644-A8F2-FAD4803C8898\%7D>. Acesso em: 02 ago. 2019.

[3] PHILIPS, Lâmpadas e tubos LED. Disponivel em: < http://www.lighting.philips.com.br/prof/lampadas-etubos-led\#pfpath=0-LED_GR>. Acesso em: 27 jul. 2019.ASSOCIAÇAO BRASILEIRA DE NORMAS TÉCNICAS. NBR ISO/CIE 8995: Iluminação de ambientes de trabalho. 1 ed. Rio de Janeiro, 2013. 46 p.

[4] SANTOS, Talia Simões et. al. Análise da eficiência energética, ambiental e econômica entre lâmpadas de LED e convencionais. Artigo técnico, 8 p. 2015.

[5] INMETRO, Instituto Nacional de Metrologia, Normalização e Qualidade Industrial. Lâmpadas LED: Confira as dicas para escolher os modelos mais econômicos. Disponivel em: < http://www4.inmetro.gov.br/node/4532>. Acesso em: 27 jul. 2019.

[6] OSRAM. Light is the key to success Lighting solutions for industry. Disponível em: < https://media.osram.info/media/img/osram-dam4764621//180426_OS_0006_17_Launchkampagne_Industry-Line_Broschuere_EN_3_RZ_Screen.pdf >. Acesso em: 27 jul $201 \overline{9}$.

[7] MORAIS JÚNIOR, Francisco Edson Gomes de. Análise da inserção de Lâmpadas LED em Prédios da UFERSA. 2019. 12f. Trabalho de Conclusão de Curso - Universidade Federal Rural do Semi-Arido, Rio Grande do Norte, 2019.

[8] ASSOCIAÇÃO BRASILEIRA DE NORMAS TÉCNICAS. NBR ISO/CIE 8995: Iluminação de ambientes de trabalho. 1 ed. Rio de Janeiro, 2013. 46 p.

[9] COSERN, Companhia Energética do Rio Grande do Norte. Tabela de Tarifas de Energia Elétrica Grupo A. Disponível em: 〈>. Acesso em: 07 ago 2019. 